\title{
Is Adiposity associated with the Quality of Movement Patterns in the Mid-Adolescent Period?
}

\author{
Josip Karuc ${ }^{1 *}$, Goran Marković ${ }^{1}$, Marjeta Mišigoj-Duraković ${ }^{1}$, Michael J. Duncan ${ }^{2}$ and Maroje \\ Sorić ${ }^{1}$ \\ 1 Faculty of Kinesiology, University of Zagreb, Croatia; goran.markovic@kif.unizg.hr (G.M.); \\ marjeta.misigoj-durakovic@kif.unizg.hr (M.M.-D.); maroje.soric@kif.unizg.hr (M.S.) \\ 2 Faculty Research Centre for Sport, Exercise and Life Sciences, Coventry University, UK; \\ aa8396@coventry.ac.uk (M.J.D.) \\ * Correspondence: josip.karuc@kif.unizg.hr (J.K.)
}

\begin{abstract}
This study investigated the relationship between functional movement (FM) and adiposity in adolescents (16-17 years). This research is a part of the CRO-PALS study conducted in a random sample of adolescents ( $n=652$, mean age $\pm S D$ : $16.6 \pm 0.4)$. Body mass index (BMI), a sum of four skinfolds (S4S), waist and hip circumference were measured, and FM was assessed via Functional Movement Screen ${ }^{\mathrm{TM}}$ (FMSTM). Multilevel analysis were employed to determine the relationship between different predictors and total FMS score. After controlling for age, moderate-to-vigorous physical activity, and socioeconomic status, relationship between variables of adiposity and total FMS score was significant and negative among boys (BMI: $\beta=-0.18, \mathrm{p}<0.0001 ; \mathrm{S} 4 \mathrm{~S}: \beta=-0.04, \mathrm{p}<0.0001$; waist circumference: $\beta=-0.08, \mathrm{p}<0.0001$; hip circumference: $\beta=-0.09, \mathrm{p}<0.0001)$. However, among girls, in adjusted models, only S4S showed a significant and negative effect on total FMS score $(\beta=-0.03$, $\mathrm{p}<0.0001$ ), while other coefficients failed to reach significance (BMI: $\beta=-0.05, p=0.23$; waist circumference: $\beta=-0.04, p=0.06$; hip circumference: $\beta=-0.01, p=0.70$ ). Results showed that the effect of adiposity on FM in adolescence is sex-specific, suggesting that boys with overweight and obesity could be more prone to develop dysfunctional movement patterns. Therefore, exercise interventions directed toward correcting dysfunctional patterns should be sex-specific, targeting more boys with overweight and obesity rather than adolescent girls with overweight and obesity.
\end{abstract}

Keywords: obesity; paediatric exercise; motor control; motor coordination; motor competence; movement competence

\section{Introduction}

Childhood obesity presents one of the largest public health problems with serious longterm health consequences. Children with obesity have a higher risk of developing diabetes type 2, cardiovascular diseases, cancer, and musculoskeletal disorders later in life [1-3]. Amongst the abovementioned risks of paediatric obesity, musculoskeletal disorders with associated biomechanical and health impact have been least studied systematically. According to the most recent umbrella review which investigated the association between adiposity and physical function in children with obesity, 
few published systematic reviews drew attention to the phenomena of the biomechanics of childhood obesity [4]. Indeed, only one review pointed to the negative influence of child overweight on movement biomechanics with possible long-term consequences on musculoskeletal health [5]. This is surprising since musculoskeletal disorders are currently among the most common diseases and one of the leading world health-care problem [6]. For example, direct costs of the musculoskeletal diseases among children in the United States amount to more than 7.6 billion USD per year [7]. In addition to this, it is well known that pathobiomechanical behaviour is a key factor for the development of postural and musculoskeletal pathologies in children and adults [8-11]. However, it remains unknown what role adolescent obesity plays in the development of different pathobiomechanical movement behaviour.

According to the recent evidence, three inter-related clinical and biomechanical components are compromised in children with overweight: 1) body posture [12-16], 2) gait biomechanics [5,17], and 3) movement competence [4,18-20]. Compared to normal weight peers, children with overweight demonstrate postural malalignments characterized by thoracic hyperkyphosis, lumbar hyperlordosis, genu valgum and varus, valgus heel, and flat feet [12-16]. Also, children with overweight have altered biomechanics of gait associated with higher hip and tibiofemoral contact force, and lower limb valgus position [5]. Additionally, during walking, these children exhibit increased maximum force beneath the lateral and medial forefoot, greater pressure-time integral beneath the midfoot and $2^{\text {nd }}-5^{\text {th }}$ metatarsal area [17]. Along with the postural abnormalities and altered biomechanics of walking, children with overweight have compromised movement competency [18-20]. Movement competency is defined as the global movement patterns (i.e. locomotion, object control skills, or stability tasks) essential for the child motor development [21,22]. An important aspect of the movement competency, and thus of motor development, is the qualitative component of the movement, often termed as the movement quality.

Functional movement (FM) represents a clinical measure of movement quality [23-25], most commonly assessed via Functional Movement Screen ${ }^{\mathrm{TM}}\left(\mathrm{FMS}^{\mathrm{TM}}\right)$ [26,27]. FM implies an optimal range of motion, balance, and postural control of the specific movement [26-28]. Contrary, dysfunctional movement (DFM) presents suboptimal movement quality and is related to a compensatory movement pattern along the kinetic chain with associated loss in the range of motion, balance, and deficit in postural control of the specific movement pattern [26-28]. The importance of FM patterns has been discussed in previous studies [23-27] and they are considered as fundamental 'pillars' for the exhibition of complex movements [26,27], whereas DFM has been related to higher injury incidence [29-32] and potential movement pathologies in children with overweight [19,20,33]. Therefore, incorporating FM patterns in exercise programs is critical for the optimal progress toward more complex movement skills [26-28]. In addition to the aforementioned consequences of obesity on biomechanics, evidence shows that higher body weight changes motor performance, range of motion [34], balance [34] and leads to poor postural control in children [35] which could potentially endanger the performance of both FM and complex movement skills. Evidence suggest that obesity has a high impact on joint structures responsible for joint stabilization and proprioception [36]. Also, obesity leads to degenerative deformities such as osteoarthritis even among children [37]. Taking everything into account, postural alteration, coordination deficits, and overweight in childhood could lead to the development of DFM and orthopaedic deformities in the future $[1,19,20]$. This could be concerning since the number of children with overweight and obesity is still increasing around the 
globe [38]. Still, among all previously considered biomechanical components, FM and its relation to the adiposity has not been studied widely.

The development of DFM patterns along with higher body weight through the adolescent period can cause even greater and negative health consequences on the musculoskeletal system. Moreover, neuromuscular control and movement coordination are not completely developed by the time of adolescence [39]. Therefore, investigating relations between adiposity and FM is important for the musculoskeletal health of the mid-adolescents as well. Only a handful of studies have focused on studying movement quality and obesity in the paediatric population with the majority reporting an inverse relationship between FM and weight status $[19,20,34,40,41]$, while only one study revealed no correlation between these two variables [42]. However, these studies have been performed on a small number of conveniently selected children, or recruited only participants with overweight/obesity, and did not include mid-adolescents. This makes it difficult to ascertain how FM and adiposity might be related during this period, and without this scientists, physical educationalists and clinicians may make erroneous decisions by applying outcomes found on children onto adolescents. To the authors' knowledge, there are no studies that investigated the relationship between FM and adiposity in a large, random sample of mid-adolescents. Therefore, this study aims to bridge this gap by examining the sex differences in FM between adolescents with normal weight and adolescents with overweight and obesity. In addition, this study will thrive to reveal the relationship between variables of adiposity and FM in in a representative sample of urban mid-adolescents.

\section{Materials and Methods}

\subsection{Participants}

This study is a part of the CRO-PALS study, a longitudinal study conducted in a random sample of urban youth in Zagreb (Croatia). Details on the sampling and procedures of the study have been described elsewhere [43]. In brief, using stratified two-stage random sampling procedures (school level and class level), 54 classes in 14 secondary schools were selected to participate in the CRO-PALS study (schools were stratified by type: grammar schools/vocational schools/private schools). All 1408 students in the selected classes were approached, and 903 agreed to participate (response rate $=64 \%$ ). One hundred and fifty-seven participants were unavailable on the day of testing or did not complete the FMS screening and anthropometric measurement. As a consequence, data from 746 adolescents were collected.

All the participants had to meet certain criteria to be included in the analyses, specifically: 1) not reporting any pain during the FMS ${ }^{\mathrm{TM}}$ testing procedure, and 2) not being classified as a child with underweight according to International Obesity Task Force criteria [44]. Accordingly, 94 subjects were excluded. Therefore, the total number of participants that was analyzed was 652 (girls, $n=321$, mean age $\pm S D=16.6 \pm 0.4$ yo; boys, $n=331$, mean age $\pm S D=16.7 \pm 0.4$ yo). Measurements were taken in 2015., during March, April, and May. The flowchart of the included participants is shown in Figure 1.

Having fully informed the children and their parents about the aims of the study, its protocol, and the possible hazards and discomforts related to the procedures used, written consent was obtained from both children and their parents or legal guardians. The study was performed 
according to the Declaration of Helsinki and the procedures were approved by the Ethics Committee of the Faculty of Kinesiology, University of Zagreb (Croatia) (No: 1009-2014).

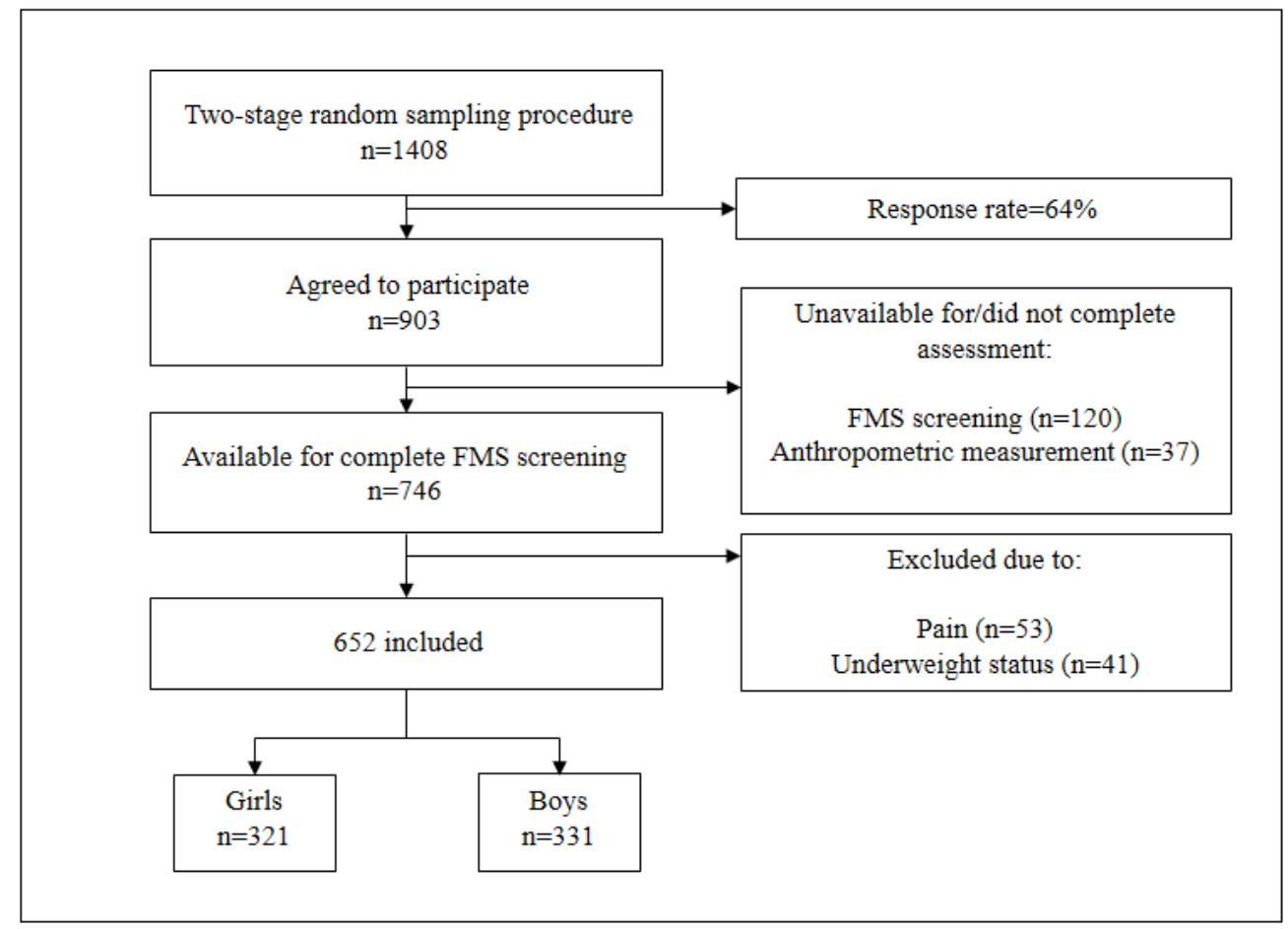

Figure 1. Flowchart of included participants.

Note: FMS screening = Functional Movement screening standardized procedure

\subsection{Procedures}

\subsubsection{Outcomes: Functional Movement Screen Variables}

FM (i.e. movement quality) was assessed via FMS'T . FMS ${ }^{\mathrm{TM}}$ is a screening instrument designed for evaluation of mobility and stability of the seven functional movement patterns through seven tests [26,27]: the deep squat, hurdle step, inline lunge, shoulder mobility, ASLR, trunk stability push-up, and rotary stability. According to previous research, two-hour education on using FMSTM is efficient to reach acceptable interrater and intrarater reliability [45]. However, the FMS ${ }^{\text {TM }}$ was performed by ten novice trained raters who underwent two-day education and training procedures by an FMSTM certified practitioner. Moreover, two familiarization sessions were conducted to optimize the consistency and accuracy of raters. Each participant had a maximum of 3 trials for each test following the recommended protocol and the highest score from the three trials was recorded [26,27]. Each test was scored on a three-point scale, from 0 to 3, with higher scores indicating better quality of movement. It has been shown that pain can alter movement control [46]. Therefore, participants were asked if they felt pain during the FMS ${ }^{\mathrm{TM}}$ testing procedure, and were subsequently scored with zero and excluded if answered positively to the question ( $n=53)$. In this study, we defined FM as the movement with a given score of 2 or 3 during FMSTM procedure. Also, a score of 1 was given when the participant was unable to perform movement due to the number of movement compensation present which reflects the DFM pattern [26-28]. This means that score of 2 and 3 was an indicator of FM, whereas a score of 1 was an indicator of DFM for each of 7 individual FMS tests. 
In this way, we could calculate the number and proportion of participants that exhibited DFM in each of the 7 individual FMS tests. This was the basic step for analyzing the differences in the proportion of participants that performed DFM between normal weight and overweight children for each of 7 individual FMS ${ }^{\mathrm{TM}}$ tests (i.e. using chi-square tests). Besides, an overall composite score (total FMS score) was calculated with a total FMS score of 21 according to standardized guidelines reported in the literature [26,27]. In this way, the total FMS score was set as a continuous outcome variable for the 2-way ANOVA and multilevel model regression analysis.

\subsubsection{Predictors: Body Mass Index, Sum of Four Skinfolds, Waist and Hip Circumference}

Participants were weighed barefoot in their shorts and T-shirts with a pre-calibrated portable digital scale to the nearest $0.1 \mathrm{~kg}$. Height was taken to the nearest $0.1 \mathrm{~cm}$ using an anthropometer (GPM, Siber-Hegner \& Co., Switzerland). Then, body mass index (BMI) was calculated as the body weight in kilograms divided by the body height in meters squared $\left(\mathrm{kg} / \mathrm{m}^{2}\right)$ [47]. Age and sex-specific BMI cut-off points proposed by the International Obesity Task Force criteria were used to distinguish between normal weight and overweight or obese children [44]. For the purpose of this study participants were separated into two weight status groups: normal weight and overweight and obese group of children. Within the group of girls with overweight and obesity, 8 girls were classified as girls with obesity (i.e. 15\%), while within the group of boys with overweight and obesity, 17 boys (20\%) were classified as children with obesity. Skinfold measurements were taken on the right side of the body at the following sites to the nearest $0.2 \mathrm{~mm}$ using Harpenden skinfold calliper (British indicators, West Sussex, UK): 1) triceps - at the back of the upper arm, halfway between the acromion process and the olecranon process, 2) biceps - at the front of the upper arm; at the same level as the triceps, 3) subscapular - about $2 \mathrm{~cm}$ below the lower angle of the scapula; a diagonal fold, 4) suprailiac - at the iliac crest; in anterior axillary line plane. All skinfold measures were taken in triplicate and median values were used for analysis. Waist and hip circumferences were measured manually with non-stretchable tape in a transverse plane at the midpoint between the last rib and the iliac crest, and at the level of the largest lateral extension of the hips, respectively [48]. Skinfold measurements and body circumferences on all participants were performed by a single, skilled lab technician.

2.2.3. Confounders: Moderate-to-vigorous physical activity (MVPA), Socioeconomic status (SES), and Age

To assess physical activity level, the School Health Action, Planning, and Evaluation System (SHAPES) questionnaire was used to assess physical activity via a computerized version [49]. This questionnaire is constituted of 45 multiple-choice questions and was specifically designed for repeated school-based surveys. Two items request a 7-d recall of vigorous physical activity (VPA) and moderate physical activity (MPA), respectively. Responses are provided by indicating the number of hours and 15-min increments that each type of physical activity was performed for each day of the previous week. Therefore, the intensity, duration, and frequency of physical activity were documented, and the total volume of physical activity was calculated. The average time during the day spent while performing MVPA was calculated by summing the weekly time spent performing VPA and MPA divided by 7. Wong et al. [49] reported that MVPA estimated using the SHAPES questionnaire correlated moderately with the values of the accelerometer device $(r=0.44)$. The results 
of this physical activity questionnaire can be comparable with other instruments for adolescents as prior reliability research using the SHAPES questionnaire showed moderate agreement for moderate and vigorous physical activity [49].

SES of adolescents was assessed by using a subjective rating of their perceived socio-economical position within the population. Perceived SES was assessed through a one-item question: "What do you think about your financial situation when you compare yourself to other peers? Think about how much you can afford.". Responses were as follows: 1 - Much lower than average, 2 - Lower than average, 3 - Average, 4 - Higher than average, 5 - Much higher than average. Additionally, chronological age was expressed in years and was added in all multilevel analyses as a confounder and centered around the value of 17 (coded as Age-17).

\subsection{Data analysis}

First, descriptive analysis for adiposity and confounder variables was done for girls and boys separately. Second, to determine the differences between the group of children with normal weight and overweight and obesity in total FMS score, a two-way ANOVA was employed, using weight status and sex as fixed factors. Third, to examine the differences between the group of children with normal weight and overweight in the proportion of individuals who performed DFM, a chi-square test was employed for boys and girls separately. Lastly, multilevel modelling was used to examine the relationship between the variables of adiposity and total FMS score.

In this research, the approach developed by the Centre for Multilevel Modelling - University of Bristol was applied [50]. Multilevel modelling is an elongation of standard multiple regression, where the data have a hierarchical or clustered structure [50]. The process of multilevel modelling was divided into three steps. In the beginning, for each predictor, we built the first model (e.g. level1 model). After that, the second model was built (e.g. level-2 model) (in this way, the first step of multilevel modelling was completed). Next, these two models were compared with the likelihood ratio test (LR test) and tested for significance (thus, the second step was completed). Thirdly, the model with a better fit was chosen (end of the third step). After the aforementioned three-step process was done, the next model (e.g. level-3 model) was introduced and this process was repeated (from first to the third step). To get the final model, this process was iterative, which resulted in the number of different models where the model with the best fit was chosen at the end (final model) [50] (Figure 2.). According to the evidence, sex has a significant influence on weight status and total FMS score during adolescence [51]. Therefore, the sample was a priori stratified by sex, and all further multilevel analyses were performed separately for boys and girls. To examine the effect of different variables of adiposity on FM, the outcome was the total FMS score with the following predictors: BMI, the sum of four skinfolds, waist circumference, and hip circumference. Age, physical activity level, and SES were introduced in all models as the confounders since they have been previously shown to influence the total FMS score [20,52]. 


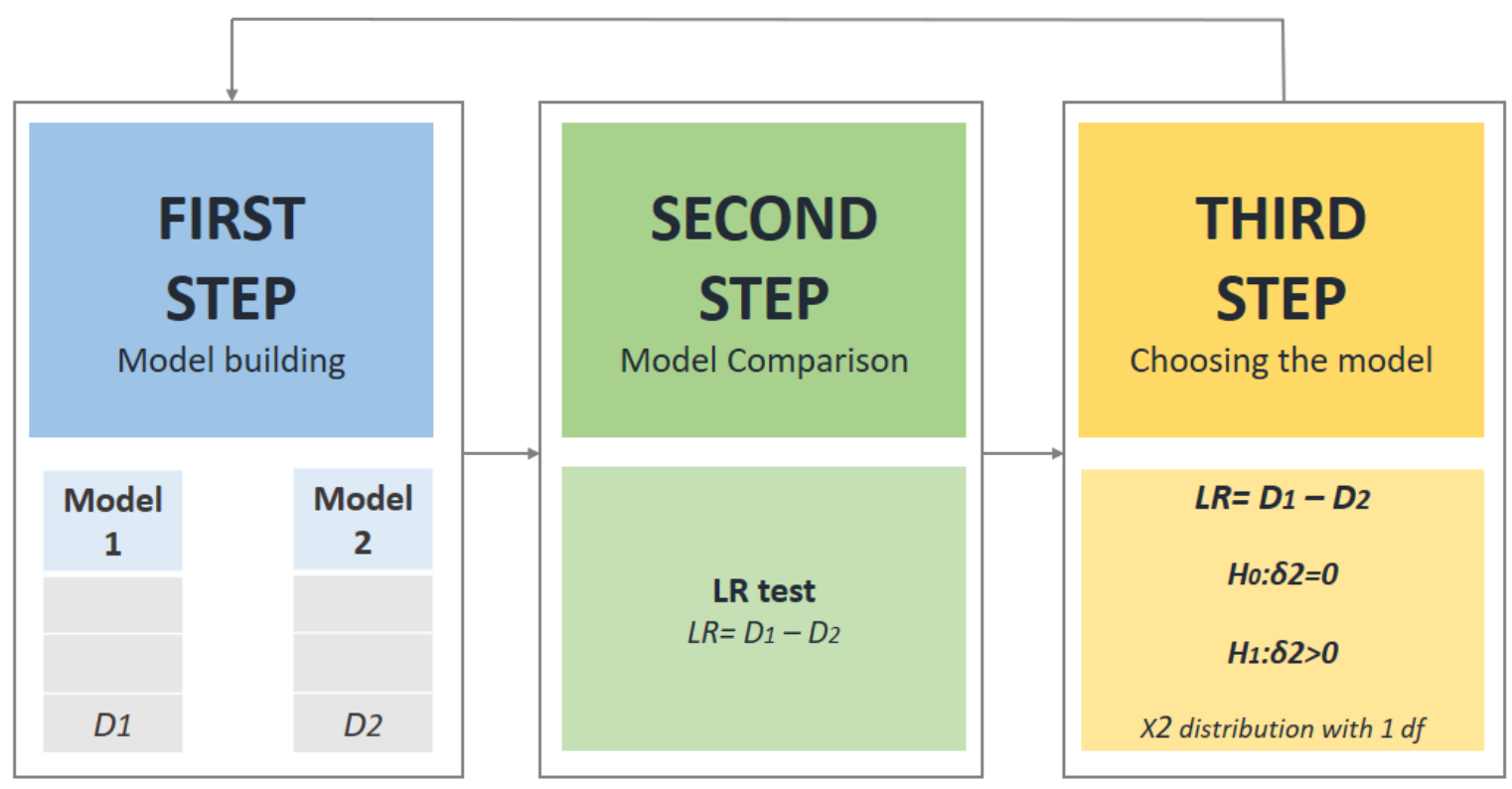

Figure 2. The simplified three-step multilevel approach.

In this study, descriptive data are presented as mean values \pm SD. Multilevel analysis was performed by using the statistical package MLwiN (version 3.04) [53] while for descriptive analysis statistical package Statistica (version 13.5) was used. The level of the statistical significance was set at $\mathrm{p}<0.05$.

\section{Results}

\subsection{Descriptive statistics}

Table 1 presents the characteristics of the participants stratified by gender. 
Table 1. Characteristics of the study sample stratified by gender.

\begin{tabular}{|c|c|c|}
\hline & Girls $(n=321)$ & Boys $(n=331)$ \\
\hline $\begin{array}{c}\text { OW \& OB within each group } \\
\text { n (\%) }\end{array}$ & $52(16.2)$ & $84(25.4)$ \\
\hline $\begin{array}{c}\text { BMI }\left(\mathrm{kg} / \mathrm{m}^{2}\right) \\
\text { mean }(\mathrm{SD})\end{array}$ & $22.1(3.0)$ & $22.6(3.4)$ \\
\hline $\begin{array}{l}\text { Sum of four skinfolds (mm) } \\
\text { mean (SD) }\end{array}$ & $49.9(14.8)$ & $37.1(17.8)$ \\
\hline $\begin{array}{c}\text { Waist circumference }(\mathrm{cm}) \\
\text { mean }(\mathrm{SD})\end{array}$ & $69.3(6.2)$ & $76.2(7.3)$ \\
\hline $\begin{array}{c}\text { Hip circumference (cm) } \\
\text { mean (SD) }\end{array}$ & $97.5(7.2)$ & $98.1(7.3)$ \\
\hline $\begin{array}{l}\text { MVPA (min/day) } \\
\text { median (IQR) }\end{array}$ & $85.7(73.5)$ & $117.9(86.3)$ \\
\hline $\begin{array}{c}\text { SES } \\
\text { median (IQR) }\end{array}$ & $3(1)$ & $2(1)$ \\
\hline
\end{tabular}

OW \& OB within each group: Number (n) and percentage (\%) of participants with overweight and obesity within each sex group; BMI: Body Mass Index; MVPA: Moderate-to-Vigorous Physical Activity; SES: socioeconomic status (1- Much lower than average, 2- Lower than average, 3- Average, 4- Higher than average, 5- Much higher than average); SD: Standard Deviation; IQR: interquartile range.

3.2. Differences between children with normal weight and children with overweight and obesity in total FMS score

Results of 2-way ANOVA showed significant effect of $\operatorname{sex}(\mathrm{F}=14.14, \mathrm{p}=0.00019)$, weight status $(\mathrm{F}=14.43, \mathrm{p}=0.00016)$, and sex ${ }^{*}$ weight status interaction $(\mathrm{F}=8.81, \mathrm{p}=0.00016)$ on total FMS score. After that, Bonferroni's post-hoc test was performed and revealed a significant difference in total FMS score within the group of boys, where boys with normal weight surpass boys with overweight and obesity in total FMS score (12.6 and 11.1, respectively; $\mathrm{p}<0.0001)$. Within the group of children with overweight and obesity, girls with overweight and obesity exhibited better results in total FMS score compared to boys with overweight and obesity (12.6 vs 11.1, respectively; $\mathrm{p}<0.0001)$. Besides, the analysis showed significant interaction, where girls with normal weight outperformed boys with overweight and obesity (total FMS score: 12.8 vs 11.1, respectively; $\mathrm{p}<0.001$ ). Results of 2-way ANOVA representing differences within sex and weight status group as well as the interaction between groups in total FMS score are presented in Table 2. 
Table 2. Results of 2-way ANOVA representing differences within the sex and weight status group as well as the interaction between groups in total FMS score.

\begin{tabular}{ccccc}
\hline & NW & OW \& OB & $\begin{array}{c}\text { within sex } \\
\text { group difference }\end{array}$ & interaction \\
\hline Girls & 12.8 & 12.6 & $p=1.00$ & $p=1.00^{1}$ \\
\hline Boys & 12.6 & 11.1 & $p<0.0001$ & $p<0.001^{2}$ \\
\hline $\begin{array}{c}\text { within weight } \\
\text { status group } \\
\text { difference }\end{array}$ & $p=1.00$ & $p<0.0001$ & & \\
\hline
\end{tabular}

NW: Group of children with normal weight status; OW \& OB: Group of children with overweight and obesity; Interaction: ${ }^{1} \mathrm{p}$-value for the difference between group of boys with NW and group of girls with $\mathrm{OW} \& \mathrm{OB} ;{ }^{2} \mathrm{p}$ value for the difference between group of girls with NW and boys with OW \&OB; Post-hoc results are obtained with Bonferroni post-hoc test.

3.3. Differences between children with normal weight and children with overweight and obesity in the proportion of individuals that performed DFM in each FMS test

Differences in the proportion (\%) of girls with normal weight and girls with overweight and obesity that performed DFM in each FMS test are shown in Figure 3. Interestingly, girls with normal weight showed a lower proportion of DFM compared to girls with overweight and obesity in only one FMS test - shoulder mobility $(21 \%$ vs $39 \%$, respectively; $\mathrm{p}=0.04)$. However, there was no difference in the proportion of individuals that performed DFM between girls with normal weight and girls with overweight and obesity in other FMS tests.

\section{$\%$ OF DFM IN GIRLS}

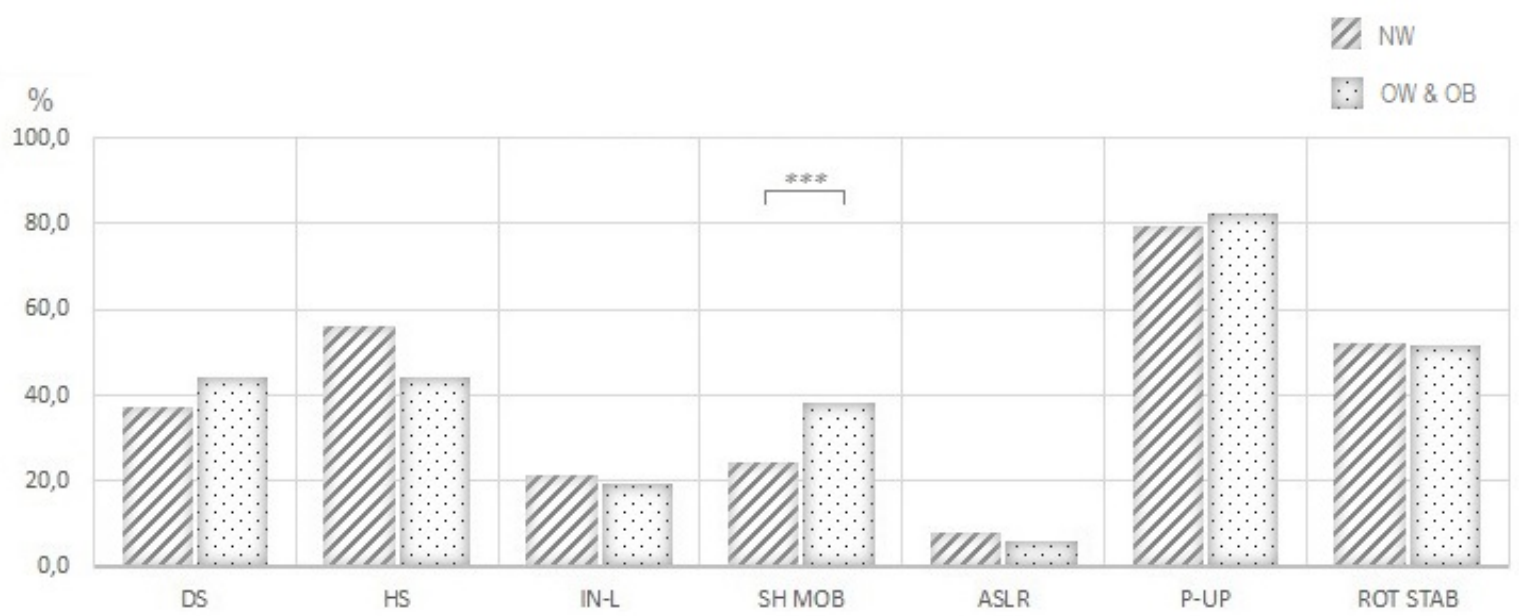

Figure 3. Proportion (\%) of girls with normal weight and girls with overweight and obesity that performed dysfunctional movement (DFM) in each FMS test. Note: \% OF DFM IN GIRLS - Proportion (\%) of girls that performed dysfunctional movement; NW - Girls with normal weight; OW \& OB Girls with overweight and obesity; DS - Deep squat; HS - Hurdle step; IN-L - Inline lunge; ASLR - 
Active straight leg raise; SHO MOB - Shoulder mobility; P-UP - Trunk stability push-up; ROT STAB - Rotary stability. ${ }^{* * *} \mathrm{p}=0.04$.

Figure 4 demonstrates differences in the proportion (\%) of boys with normal weight and boys with overweight and obesity that performed DFM in each FMS test. Boys with normal weight exhibited better quality of movement and lower proportion of DFM compared to boys with overweight and obesity in most of the FMS tests: deep squat ( $30 \%$ vs $51 \%$, respectively; $\mathrm{p}<0.0001$ ), inline lunge ( $29 \%$ vs $43 \%$, respectively; p $<0.0001$ ), shoulder mobility ( $41 \%$ vs $59 \%$, respectively; $\mathrm{p}=0.01$ ), trunk stability push-up ( $33 \%$ vs $62 \%$, respectively; $\mathrm{p}<0.0001)$, and rotary stability $(32 \%$ vs $59 \%$, respectively; $\mathrm{p}<0.0001$ ).

\section{$\%$ OF DFM IN BOYS}

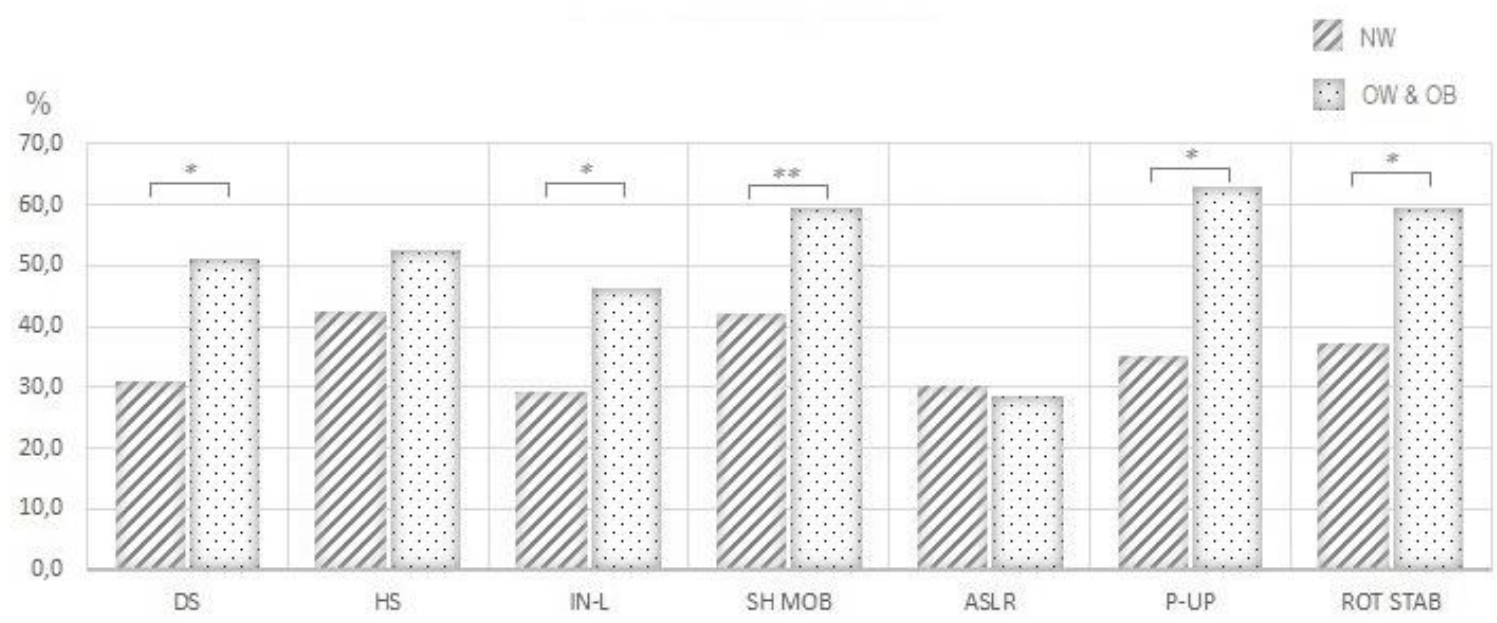

Figure 4. Proportion (\%) of boys with normal weight and boys with overweight and obesity that performed dysfunctional movement (DFM) in each FMS test. Note: \% OF DFM IN BOYS - Proportion (\%) of boys that performed dysfunctional movement; NW - Boys with normal weight; OW \& OB Boys with overweight and obesity; DS - Deep squat; HS - Hurdle step; IN-L - Inline lunge; ASLR Active straight leg raise; SHO MOB - Shoulder mobility; P-UP - Trunk stability push-up; ROT STAB - Rotary stability. ${ }^{*} \mathrm{p}<0.0001,{ }^{* *} \mathrm{p}=0.01$.

\subsection{Relationship between the variables of adiposity and total FMS score}

Since this study investigated high school children, in the current study, data have a three-level hierarchical structure where students are at level-1, nested within classes at level-2 nested within schools at level-3. After introducing variance-component models at level-1, level-2, and level-3, the variation partition coefficient (VPC) was calculated to obtain information on how much clustering there was in the data. VPC showed significant clustering among both sexes (among girls: VPC $=0.919$; among boys: $\mathrm{VPC}=0.865$ ), indicating that $8.1 \%$ and $13.5 \%$ of total FMS score variation lies within classes, and $91.9 \%$ and $86.5 \%$ of variation lies between girls and boys, respectively. Expressed as an intraclass correlation coefficient (ICC), where VPC $=I C C$, the correlation in total FMS score within classes is 0.09 for girls, and 0.13 for boys; suggesting that clustering or non-independence exists in our data. This was also evident after plotting the total FMS scor by schools (see Appendix A, Fig. A1). 
When the level-3 model was introduced, level-3 deviance (D3) dropped only by 0.25 and 0.6 , in girls and boys respectively; and the level-3 model was therefore not significant (among girls: LR=D2D3=1460.567-1460.317=0.25; among boys: LR=D2-D3=1520.92-1520.32=0.6). However, deviance at level-2 (D2) dropped significantly among both sexes (among girls: LR=D1-D2=1460.1451460.567=5.78; among boys: LR=D1-D2=1534.85-1520.92=13.93). We performed quantile-quantile plots (Q-Q plots) to assess assumptions made about residuals for the class (level-2) and students level (level-1) according to the literature [50]. The plots showed an approximately straight line, suggesting that the normality assumption at level-two and level-one is reasonable among girls and boys.

After the initial investigation of hierarchical data, the three-step multilevel approach was carried on as described in section 2.3. Data Analysis (see also Figure 2.). The random-intercept model was built first and included one of the predictors (e.g. BMI) with confounders: age, MVPA, and SES. Next, a random-slope model for one of the predictors (e.g. BMI) was built. After that, these models were compared with an LR test. LR test was performed to choose the model with a better fit according to the literature [50]. Finally, in all analyses, all coefficients of predictor variables were modeled as random at level-two. Accordingly, each of the predictors was analyzed in a separate analysis which resulted in eight separate analyses (four for girls and four for boys) (see Table 3.). The coefficients shown in the tables are mean unstandardized coefficients $(\beta)$ representing relationships between total FMS score and the different predictors. Mostly, the addition of confounders did not result in the improvement of the fit statistic as well as in the significance of the associated coefficient. However, nonsignificant confounders were retained in the models since they can influence the predictor coefficient [54].

\subsubsection{Effect of indicators of adiposity on total FMS score in Girls}

First, as a part of the multilevel approach, correlation analysis between BMI, the sum of four skinfolds, waist circumference, hip circumference, and total FMS score were employed separately. Results showed significant relationship between total FMS score and sum of four skinfolds ( $r=-0.199$, $\mathrm{p}<0.0001$ ), while relationship with other predictors failed to reach significance (BMI: $r=-0.05, p=0.353$; waist circumference: $\mathrm{r}=-0.095$, $\mathrm{p}=0.091$; hip circumference: $\mathrm{r}=-0.0075, \mathrm{p}=0.894$ ) (see Appendix A, Fig. A2.). After that, the multilevel modelling approach was employed. In the evaluation of the effects of different predictors on total FMS score, models with the best fit in girls resulted in random-intercept models at level-2. When the models were adjusted for age, MVPA, and SES, only the sum of four skinfolds showed a significant effect on the total FMS score $(\beta=-0.03, p<0.0001)$, while the coefficient for waist circumference approached significance $(\beta=-0.04, p=0.06)$. On the other hand, coefficients for BMI and hip circumference failed to reach significance $(\beta=-0.05, \mathrm{p}=0.23 ; \beta=-0.01, \mathrm{p}=0.70$, respectively) (Table 3).

\subsubsection{Effect of indicators of adiposity on total FMS score in Boys}

In boys, correlation analysis showed significant relationship between total FMS score and all predictors (BMI: $r=-0.2596, p<0001$; sum of four skinfolds: $r=-0.327, p<0.0001$; waist circumference: $\mathrm{r}=-0.2639$, $\mathrm{p}=0.0001$; hip circumference: $\mathrm{r}=-0.2775, \mathrm{p}=0.0001$ ) (see Appendix A, Fig. A3.). Following this, the evaluation of the effects of BMI, the sum of four skinfolds, waist and hip circumferences on total FMS score, resulted in random-intercept models at level-two as the models with the best fit. 
When the models were adjusted for age, MVPA, and SES, all predictors demonstrated significant associations with total FMS score (BMI: $\beta=-0.18, p<0.0001$; sum of four skinfolds: $\beta=-0.04, p<0.0001$; waist circumference: $\beta=-0.08, p<0.0001$; hip circumference: $\beta=-0.09, p<0.0001$ ) (Table 3.). For example, in the above analysis of the relationship between total FMS score and BMI in boys, the slope coefficient for BMI was estimated to be -0.18 and it is shared by all classes (see Table 3.). This means that a 5-point increase in BMI, therefore, corresponds to a near to 1-point decrease in total FMS score among boys, holding other confounders constant. When evaluating these coefficients, it is important to consider that each of the coefficients represents a relationship that was adjusted for the other confounders because age, MVPA, and SES were included in every analysis.

Table 3. Relationship between variables of adiposity and total FMS score among girls and boys.

response

\begin{tabular}{|c|c|c|c|c|c|c|c|c|c|c|c|c|}
\hline \multirow{2}{*}{$\begin{array}{l}\text { predictor } \\
\text { parameter }\end{array}$} & \multicolumn{3}{|c|}{ BMI } & \multicolumn{3}{|c|}{$\begin{array}{l}\text { Sum of Four } \\
\text { Skinfolds }\end{array}$} & \multicolumn{3}{|c|}{$\begin{array}{c}\text { Waist } \\
\text { circumference }\end{array}$} & \multicolumn{3}{|c|}{$\begin{array}{c}\text { Hip } \\
\text { circumference }\end{array}$} \\
\hline & $\beta$ & S.E. & $\mathbf{p}$ & $\beta$ & S.E. & p & $\beta$ & S.E. & p & $\beta$ & S.E. & $\mathbf{p}$ \\
\hline Girls & -0.05 & 0.04 & 0.23 & -0.03 & 0.01 & 0.0001 & -0.04 & 0.02 & 0.06 & -0.01 & 0.02 & 0.70 \\
\hline Boys & -0.18 & 0.04 & 0.0001 & -0.04 & 0.01 & 0.0001 & -0.08 & 0.02 & 0.0001 & -0.09 & 0.02 & 0.0001 \\
\hline
\end{tabular}

total FMS score: total Functional Movement Screen score; BMI: Body Mass Index; $\beta$ : beta unstandardized coefficient; S.E.: Standard Error; p: p-value. All models are adjusted for age (centered around the value of 17), MVPA, and SES.

\section{Discussion}

To our knowledge, this is the first study that has analyzed sex differences in FM between children with normal weight and children with overweight and obesity in the mid-adolescent period. The strength of our approach is seen in large sample size, separate analyses of girls and boys, control of known confounding variables (i.e., age, physical activity level, and SES), and the use of several variables of adiposity in analyses. The key findings of the present study are related to: (a) sex-specific differences in total and individual FMS scores between adolescents with normal weight and adolescents with overweight and obesity, and (b) generally low, but sex-specific, relationship between variables of adiposity and total FMS score in adolescents.

Performance of our participants in FMS was comparable to those of 13-18-year old highschool athletes [55] but lower than those of Indian adolescents recreationally or competitively participating in sports [51]; however, the studied sample in the latter study had a much wider age range (i.e., 10-17 years). Given that age and maturity status could have a significant effect on the FMS score [56], it could be a plausible reason for the observed discrepancy in findings. In the present study, we have not observed practically relevant sex differences in total FMS score considering the total sample. This is in contrast to findings obtained on recreational or competitive adolescent athletes [51,57], where boys significantly outperformed girls in total FMS score (mean difference: 0.8-1.5). 
Thus, it seems that, at least in adolescents, sports participation could significantly affect sex-related differences in total FMS score.

In the current study, boys with overweight and obesity, but not girls, had significantly lower total FMS score compared to their peers with normal weight, suggesting that the effect of adiposity on movement quality in adolescents could be sex-specific. This finding is reinforced by the results of multilevel analyses, which showed a statistically significant relationship between variables of adiposity and total FMS score in boys, but not in girls. A previous study conducted by Duncan et al. [19] reported significantly lower FMS scores in overweight/obese group vs. normal weight group of school children (7-10 yo), but did not include a separate analysis for each sex. To date, only one study examined sex dimorphism in regards to adiposity and FM and did not reveal a sex difference in total FMS score within group of children with normal weight, overweight or obesity [34]. Also, the same study did not report a significant difference in total FMS score between group of boys with normal weight and overweight, which is contrary to results reported in the current study. It should be noted that higher proportion of children with obesity was higher among boys compared to girls in the current study which could partly drive sex differences noted here. However, these findings are difficult to compare since the previously mentioned study included much younger participants $(9.6$ \pm 1.5 yo) with a larger age span (6-13 yo) [34]. Overall, our results suggest, for the first time, that sex has a significant effect on the relationship between movement proficiency and variables of adiposity in children and adolescents.

There are two possible explanations behind the observed sex-specific relationship between adiposity and movement quality in adolescents. 1) Neuromechanical: Evidence shows that adolescent boys are more prone to develop postural misalignment, such as hyperkyphosis compared to girls $[16,58]$; since kyphotic posture decreases concentric activity of the thoracic paraspinal muscles, this could directly limit shoulder mobility test whereas this movement pattern requires active thoracic extension (i.e. demands concentric action of the paraspinal thoracic extensors muscles) [26-28]. Moreover, hyperkyphosis can directly limit the optimal performance of the squat, inline lunge, and rotary stability since these patterns demand maintaining neutral spine position and co-contraction of the paraspinal thoracic muscles [26-28]. Also, flat feet are mostly seen in boys with overweight rather than in girls with overweight [59] which can cause deficits in uni- and contra- lateral lower-extremity stability movement patterns (i.e. in-line lunge and hurdle step) [26-28]. Furthermore, adolescent boys with obesity demonstrate impairment of the rectus femoris muscle activation which is recruited while performing lower extremities movement patterns [60]. 2) Physiological: Sex-specific effect of adiposity on movement quality is likely to be the result of the maturation process, which differs between girls and boys and may have different impacts on movement proficiency during childhood and adolescence [61]. Looking altogether, deficits which arose from each FMSTM test resulted in decrease of the total FMS score among boys, but not girls. In the present study, regardless of the measure of adiposity used, common variance between adiposity and total FMS score did not exceed $10 \%$. Previous studies have reported considerably larger inverse associations between BMI and FMS scores then in the current study ( $r$ ranged from -0.3 to -0.81 ) [19,20,34,40,41]. Notably, several studies have reported that the strength of the association between BMI and motor coordination declines as children start to reach puberty [62,63], which might explain some of the above-mentioned disparity in findings between the current and previous research.

Although our results shed some new light on the association of adiposity and movement quality of adolescents, measured with the total FMS score, this approach could be methodologically 
limited, primary because of the poor factorial validity of the total FMS score. Several exploratory factor analyses of individual FMS tests have consistently reported in both youth and adults that the 7 tasks of FMS ${ }^{\mathrm{TM}}$ have low internal consistency and were not indicators of a single factor [64-66]. Indeed, a 2-factor structure of individual FMS scores has been always observed, with extracted factors explaining only $38-47 \%$ of the variance of all 7 FMSTM tests, and with inconsistent and noninterpretable factor structure among different populations. As a result, the sum score of all FMSTM tests does not represent a consistent and valid measure of human movement quality. This is particularly problematic during growth and maturation when differentiation of general movement coordination and motor qualities is occurring [55].

When the focus is shifted to individual FMS ${ }^{\mathrm{TM}}$ tests, the limitation of particular tests, and consequently, the total FMS score to discriminate adolescents of different body size or composition becomes obvious. First, both our and several previous studies $[51,55,57]$ have shown that female participants exhibit the worst performance in trunk stability push up, which is essentially a trunk and upper-body strength test, not a trunk stabilization test. In our case, $80 \%$ of girls with normal weight failed to perform trunk stability push up correctly, suggesting that the test was too difficult even for girls with normal body weight (Figure 3.). Second, ASLR, which is essentially a flexibility test of the posterior leg, was too easy for adolescent girls, as only about $5 \%$ of them had a dysfunctional pattern in that test (Figure 3.). As a result, both tests failed to contribute to the discriminatory power of the total FMS score when comparing adolescent girls with different body composition. Of the remaining five FMSTM tests, only the shoulder mobility test significantly discriminated adolescent girls with normal weight and girls with overweight. Notwithstanding the possibility that movement quality in adolescence is indeed less affected by adiposity in females, results of this large cross-sectional study question the usefulness of some FMSTM tests in assessing movement quality of adolescent girls. In contrast, in boys, 5 out of 7 FMS $^{\text {TM }}$ tests discriminated between those with normal weight and those with overweight and obesity (Figure 4).

Still, the general question remains: 'How could overweight and obesity contribute to nonoptimal movement quality and what are the potential consequences of DFM in adolescents?'. The possible answer could give a concept which is modified according to the model proposed by Page et al. [67]. This modified concept (i.e. model of musculoskeletal dysfunction cycle and contribution of obesity in the potential development of DFM patterns), consists of the seven stages (Figure 5). Evidence shows that higher body weight puts additional load on the joints [36], which along with the sedentary behaviour and physical inactivity can create muscle imbalances in overweight children [60] (stage 1) and lead to poor postural control [35] (stage 2). Compromised posture is associated with DFM patterns in overweight children [33] (stage 3). These DFM obesity-associated patterns could result in faulty motor program (stage 4) and altered proprioception (stage 5) with possible long-term consequences on musculoskeletal health, mainly joint degeneration [37] (stage 6) and body pain (stage 7). All aforementioned stages are presented as the separate elements within the presented model, where DFM, obesity, and gender could hypothetically play a significant role for the development of the postural pathologies in adolescents. Accordingly, current study could add important piece of information within this cycle. However, further longitudinal and intervention studies are needed in order to investigate impact of obesity on FM and musculoskeletal health in adolescent population. Inclusive, both overweight and obesity negatively affect the quality of FM in adolescents which could impact musculoskeletal health later in life. Therefore, exercise interventions that targets both obesity 
and DFM needs to be incorporated into youth physical activity programs, school's curriculum and youth sports.

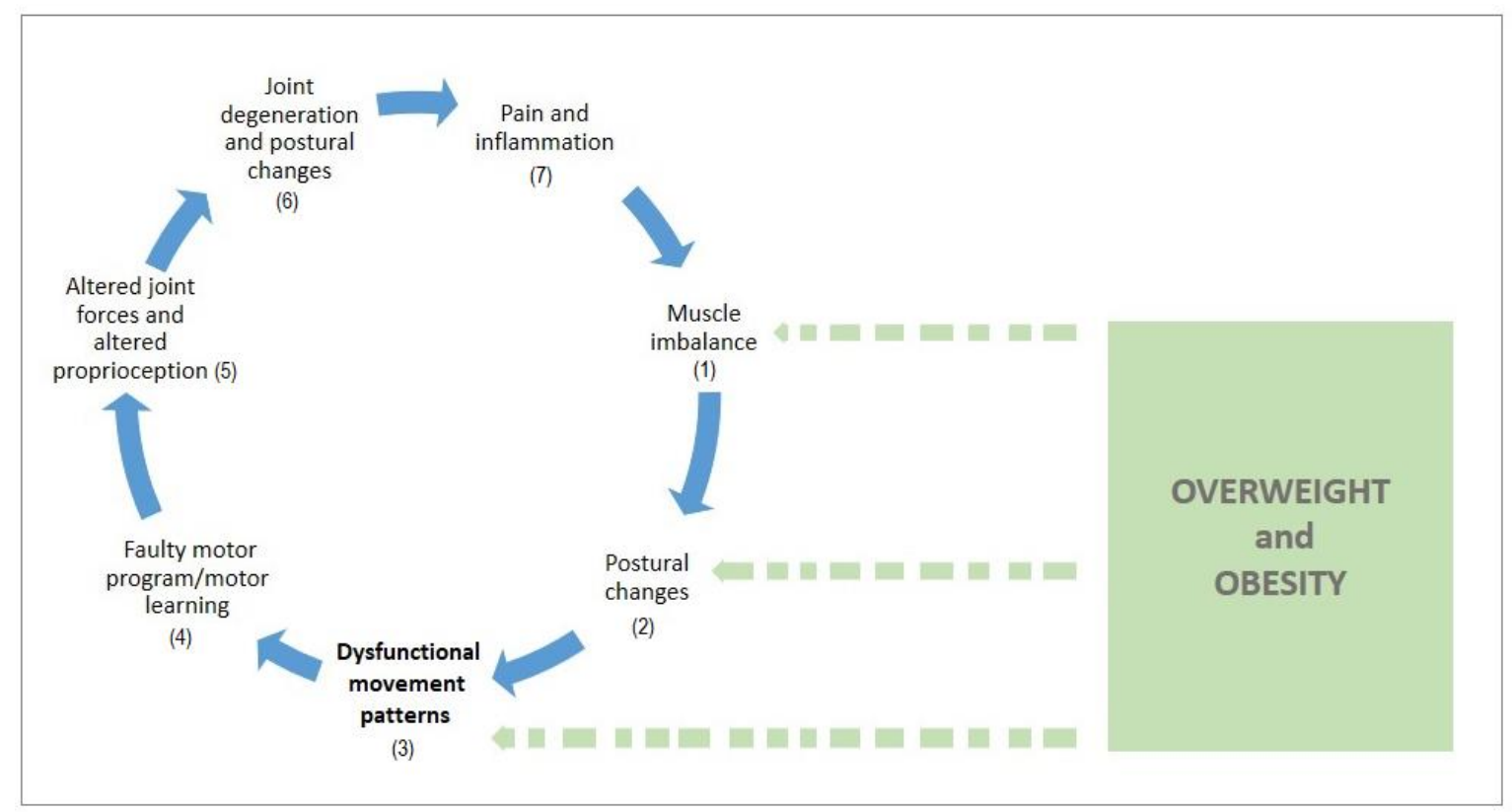

Figure 5. Model of musculoskeletal dysfunction cycle and contribution of obesity in the potential development of DFM patterns (modified according to Page et al., 2010).

\subsection{Strengths and Limitations}

There are many key strengths of this study that should be highlighted. To the authors knowledge, this is the first study that has investigated the relationship between movement quality and adiposity in the general population of mid-adolescents. Second, a large, age-homogeneous sample of mid-adolescents were recruited in this research $(n=652)$. Third, this is the only study that has applied the multilevel modelling to predict FM via various parameters of adiposity in the pediatric population. This approach resulted in less biased results (e.g. ecological fallacy is reduced) and clearer conclusions can be drawn. Fourth, this is the only study that investigated relationship between adiposity variables and total FMS score in mid-adolescent for boys and girls separately. This approach gave a new and valuable information about sex-specific relationships between FM and adiposity variables. Fifth, in this study adiposity was represented via four different indicators which can give deeper insight into relation between adiposity and FM. Last, this study controlled for a multitude of different variables that should allow a more accurate prediction of FM (age, MVPA, and SES). However, there are also some limitations that need to be acknowledged. This study has a crosssectional design that limits causal interpretations. Next, in this research, 10 raters were recruited which could influence consistency of the results. However, all raters underwent the same education and FMS testing protocol and previous studies consistently showed good interrater agreement in the FMS scores [45,68]. Also, a higher proportion of children with obesity among boys compared to girls, could drive some of the sex differences in the association of adiposity and FM reported here. Finally, 
this research included mostly urban adolescent population, while excluding adolescents from rural areas. This can potentially limit the generalizability of the results.

\section{Conclusions}

Up to this point, there are no studies that have examined the relationship between a variety of adiposity indicators and FM in the mid-adolescents. Therefore, results of the present study extent previous knowledge on another population. The current study presents novel data demonstrating that overweight and obesity has a detrimental effect on movement quality, as assessed by the FMSTM, in boys, but not girls. Of particular note, although FMS scores were poorer in boys with overweight compared to boys with normal weight, being overweight and obesity did not appear to confer the same detriment on quality of movement in girls. This means that the effect of adiposity on FM in adolescence is sex-specific, suggesting that boys with overweight and obesity could be more prone to develop dysfunctional movement patterns. Development of the optimal movement quality during adolescence is crucial step towards improving musculoskeletal health in girls and boys with overweight and obesity. More precisely, exercise interventions directed toward correcting dysfunctional patterns should be, to some degree, sex-specific, targeting more boys with overweight and obesity than girls with overweight. However, practicing FM patterns in both girls and boys with overweight and obesity could be helpful in order to potentially reduce the injury risk and future development of the postural pathologies in course of the adulthood. Looking altogether, results of the current study provide important information on the potential negative impact of adiposity on movement quality in the population of average mid-adolescents. These information is particularly important for physical therapist and coaches in youth sport, physical education teachers, and those working in the public health sector.

Author Contributions: Conceptualization: J. K., G.M., M.J.D. and M.S.; Data curation: J.K., M.M.-D. and M.S.; Formal analysis: J.K. and M.S.; Funding acquisition: M.M.-D. and M.S.; Investigation: M.M.D. and M.S.; Methodology: J.S., G.M., M.J.D., M.S. and M.M.-D; Project administration: M.M.-D and M.S.; Resources: M.M.-D and M.S.; Software: M.S. and J.K.; Supervision: M.M.-D and M.S.; Validation: G.M., M.S. and M.M.-D; Visualization: J.K.; Writing - original draft: J. K., G.M., M.J.D. and M.S; Writing - review \& editing: J. K., G.M., M.J.D., M.S and M.M.-D.

Funding: This work is a part of the Croatian physical activity in adolescence longitudinal study (CRO-PALS), funded by the Croatian Science Foundation under the grant no. IP-2016-06-9926. J.K. was funded by the Croatian Science Foundation under grant no: DOK-2018-01-2328.

Acknowledgments: The authors wish to thank Luka Blaževic, Marino Pašuld, Aleksandar Trbojević, Marko Bičanić, Filip Bolčević, Roko Buljanović, Marko Stepić, and Sandro Venier for assistance in FMS testing procedures in this study. Special thanks go to Nataša Kustura for language assistance services and Mario Jelčić for invaluable consultations and assistance on FMS testing procedures. Also, the authors wish to thank Nikola Zagorac and Ivan Karuc for consultations and their special contribution to this article.

Conflicts of Interest: The authors declare no conflict of interest. 


\section{Appendix A}

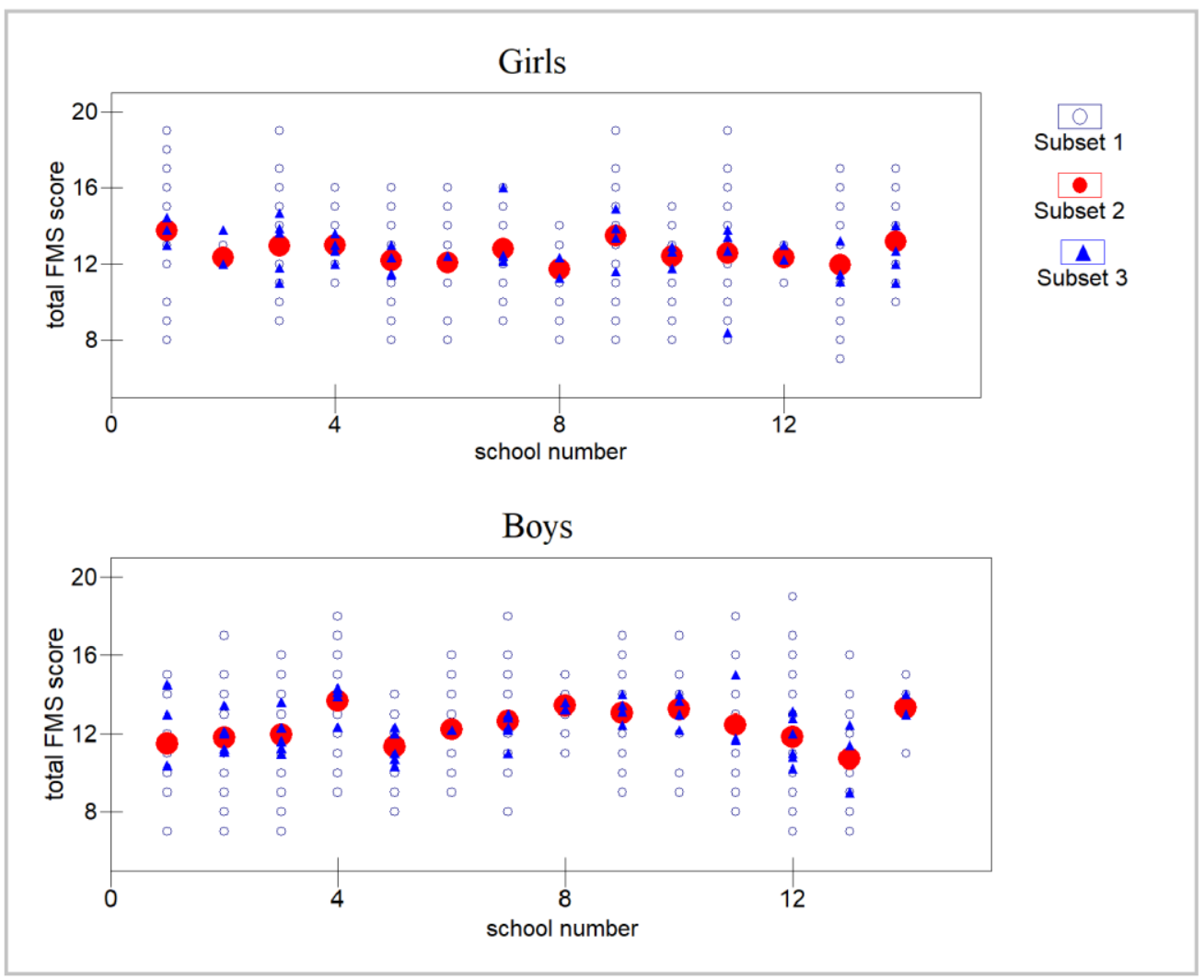

Figure A1. Scatterplot of total FMS score by school number for boys and girls separately. Subset 1 students, Subset 2- classes, Subset 3- schools.
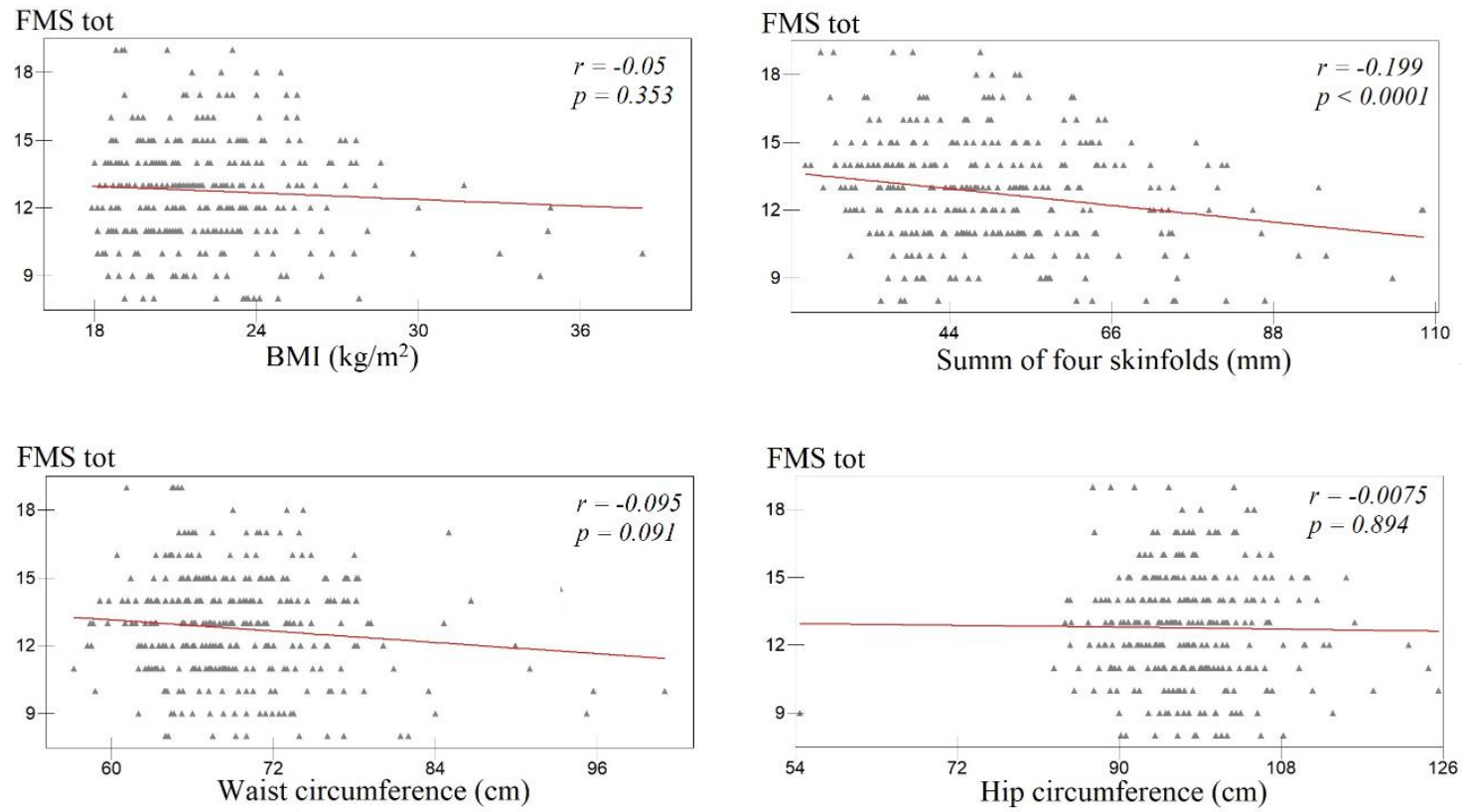

Figure A2. Correlation between BMI, sum of four skinfolds, waist and hip circumference and total FMS score among girls. 

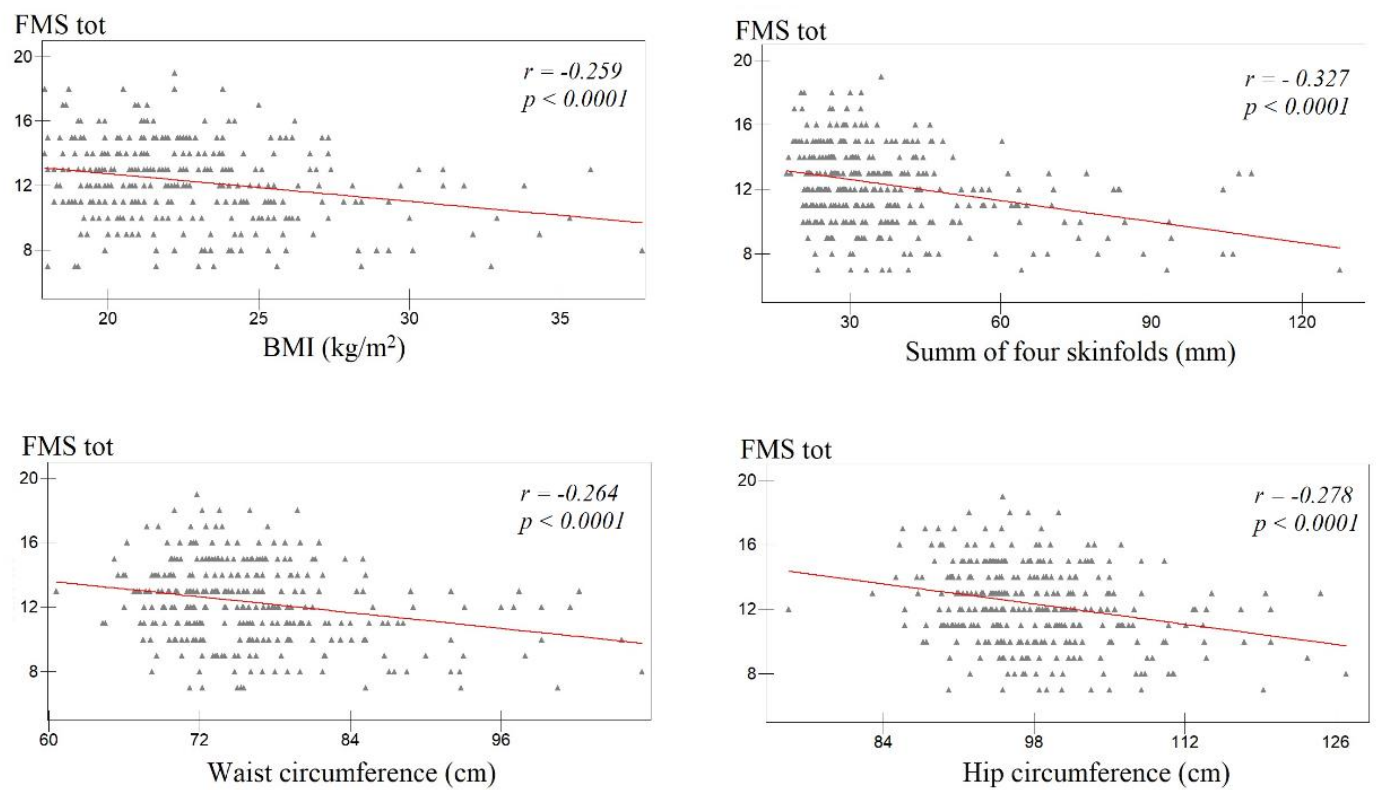

Figure A3. Correlation between BMI, sum of four skinfolds, waist and hip circumference and total FMS score among boys.

\section{References}

1. Merder-Coşkun, D.; Uzuner, A.; Keniş-Coşkun, Ö.; Çelenlioğlu, A.E.; Akman, M.; Karadağ-Saygi, E. Relationship between obesity and musculoskeletal system findings among children and adolescents. Turkiye Fiz. Tip ve Rehabil. Derg. 2017, 63, 207-214. doi: 10.5606/tftrd.2017.422.

2. Weihrauch-Blüher, S.; Schwarz, P.; Klusmann, J. H. Childhood obesity: increased risk for cardiometabolic disease and cancer in adulthood. Metabolism 2019, 92, 147-152. doi: 10.1016/j.metabol.2018.12.001.

3. Krul, M.; Van Der Wouden, J.C.; Schellevis, F.G.; Van Suijlekom-Smit, L.W.A.; Koes, B.W. Musculoskeletal problems in overweight and obese children. Ann. Fam. Med. 2009, 7, 352-356. doi: 10.1370/afm.1005.

4. Tsiros, M.D.; Tian, E.J.; Shultz, S.P.; Olds, T.; Hills, A.P.; Duff, J.; Kumar, S. Obesity, the new childhood disability? An umbrella review on the association between adiposity and physical function. Obes. Rev. 2020, 12, 26-36. doi: 10.1111/obr.13121.

5. Molina-Garcia, P.; Migueles, J.H.; Cadenas-Sanchez, C.; Esteban-Cornejo, I.; Mora-Gonzalez, J.; RodriguezAyllon, M.; Plaza-Florido, A.; Vanrenterghem, J.; Ortega, F.B. A systematic review on biomechanical characteristics of walking in children and adolescents with overweight/obesity: Possible implications for the development of musculoskeletal disorders. Obes. Rev. 2019, 20, 1033-1044. doi: 10.1111/obr.12848.

6. Briggs, A.M.; Cross, M.J;; Hoy, D.G.; Sànchez-Riera, L.; Blyth, F.M.; Woolf, A.D.; March, L. Musculoskeletal Health Conditions Represent a Global Threat to Healthy Aging: A Report for the 2015 World Health Organization World Report on Ageing and Health. Gerontologist 2016, 56, S243-S255. doi: 10.1093/geront/gnw002.

7. Rosenfeld, S.B.; Schroeder, K.; Watkins-Castillo, S.I. The Economic Burden of Musculoskeletal Disease in Children and Adolescents in the United States. J. Pediatr. Orthop. 2018, 38, e230-e236. doi: 10.1097/BPO.0000000000001131.

8. Kozak, A.; Schedlbauer, G.; Wirth, T.; Euler, U.; Westermann, C.; Nienhaus, A. Association between workrelated biomechanical risk factors and the occurrence of carpal tunnel syndrome: An overview of systematic reviews and a meta-analysis of current research. BMC Musculoskelet. Disord. 2015, 16, 1-19. doi: 10.1186/s12891-015-0685-0.

9. Mahmoud, N.F.; Hassan, K.A.; Abdelmajeed, S.F.; Moustafa, I.M.; Silva, A.G. The Relationship Between Forward Head Posture and Neck Pain: a Systematic Review and Meta-Analysis. Curr. Rev. Musculoskelet. Med. 2019, 12, 562-577. doi: 10.1007/s12178-019-09594-y.

10. Aderem, J.; Louw, Q. A. Biomechanical risk factors associated with iliotibial band syndrome in runners: A systematic review Rehabilitation, physical therapy and occupational health. BMC Musculoskelet. Disord. 2015, 16, 7-9. doi: 10.1186/s12891-015-0808-7. 
11. Boling, M.C.; Padua, D.A.; Marshall, S.W.; Guskiewicz, K.; Pyne, S.; Beutler, A. A prospective investigation of biomechanical risk factors for Patellofemoral pain syndrome: The joint undertaking to monitor and prevent acl injury (JUMP-ACL) Cohort. Am. J. Sports Med. 2009, 37, 2108-2116. doi: $10.1177 / 0363546509337934$.

12. Maciałczyk-Paprocka, K.; Stawińska-Witoszyńska, B.; Kotwicki, T.; Sowińska, A.; Krzyżaniak, A.; Walkowiak, J.; Krzywińska-Wiewiorowska, M. Prevalence of incorrect body posture in children and adolescents with overweight and obesity. Eur. J. Pediatr. 2017, 176, 563-572 .doi: 10.1007/s00431-017-28734.

13. Brzeziński, M.; Czubek, Z.; Niedzielska, A.; Jankowski, M.; Kobus, T.; Ossowski, Z. Relationship between lower-extremity defects and body mass among polish children: A cross-sectional study. BMC Musculoskelet. Disord. 2019, 20, 1-9. doi: 10.1186/s12891-019-2460-0.

14. Araújo, F.A.; Martins, A.; Alegrete, N.; Howe, L.D.; Lucas, R. A shared biomechanical environment for bone and posture development in children. Spine J. 2017, 17, 1426-1434. doi: 10.1016/j.spinee.2017.04.024.

15. Lonner, B.S.; Toombs, C.S.; Husain, Q.M.; Sponseller, P.; Shufflebarger, H.; Shah, S.A.; Samdani, A. F.; Betz, R.R.; Cahill, P.J.; Yaszay, B.; Newton, P.O. Body Mass Index in Adolescent Spinal Deformity: Comparison of Scheuermann's Kyphosis, Adolescent Idiopathic Scoliosis, and Normal Controls. Spine Deform. 2015, 3, 318-326. doi: 10.1016/j.jspd.2015.02.004.

16. Jankowicz-Szymańska, A.; Bibro, M.; Wodka, K.; Smola, E. Does excessive body weight change the shape of the spine in children? Child. Obes. 2019, 15, 346-352. doi: 10.1089/chi.2018.0361.

17. Catan, L.; Amaricai, E.; Onofrei, R.R.; Popoiu, C.M.; Iacob, E.R.; Stanciulescu, C.M.; Cerbu, S.; Horhat, D.I.; Suciu, O. The impact of overweight and obesity on plantar pressure in children and adolescents: A systematic review. Int. J. Environ. Res. Public Health 2020, 17, 1-21. doi: 10.3390/ijerph17186600.

18. Pill, S.; Harvey, S. A Narrative Review of Children's Movement Competence Research 1997-2017. Phys. Cult. Sport. Stud. Res. 2019, 81, 47-74. doi: 10.2478/pcssr-2019-0005.

19. Duncan, M.J.; Stanley, M.; Leddington Wright, S. The association between functional movement and overweight and obesity in British primary school children. Sport. Med. Arthrosc. Rehabil. Ther. Technol. 2013, 5, 1-8. doi: 10.1186/2052-1847-5-11.

20. Duncan, M.J.; Stanley, M. Functional movement is negatively associated with weight status and positively associated with physical activity in British primary school children. J. Obes. 2012, 2012, 1-5. doi: 10.1155/2012/697563.

21. Ahnert, J.; Schneider, W.; Bös, K. Developmental changes and individual stability of motor abilities from the preschool period to young adulthood. In Human development from early childhood to early adulthood: Evidence from the Munich longitudinal study on the genesis of individual competencies (LOGIC), 1st ed.; Schneider, W.; Bullock, M.; Psychology Press: New York, United States of America, 2009; pp. 54-57.

22. Stodden, D.F.; Goodway, J.D.; Langendorfer, S.J.; Roberton, M.A.; Rudisill, M.E.; Garcia, C.; Garcia, L.E. A developmental perspective on the role of motor skill competence in physical activity: An emergent relationship. Quest 2008, 60, 290-306. doi: 10.1080/00336297.2008.10483582.

23. Bernardes Marques, V.; Menezes Medeiros, T.; de Souza Stigger, F.; Yuzo Nakamura, F.; Manfredini Baroni, B. The funcional Movement Screen (FMS ${ }^{\mathrm{TM}}$ ) in elite young soccer players between 14 and 20 years: composite score, individual-test scores and asymmetries. Int. J. Sports Phys. Ther. 2017, 12, 977-985. doi: 10.16603/ijspt20170977.

24. Kraus, K.; Schütz, E.; Taylor, W.R.; Doyscher, R. Efficacy of the functional movement screen: a review. J. Strength. Cond. Res. 2014, 28, 3571-3584. doi: 10.1519/JSC.0000000000000556

25. Silva, B.; Rodrigues, L.P.; Clemente, F.M.; Cancela, J. M.; Bezerra, P. Association between motor competence and functional movement screen scores. PeerJ 2019, 7, 1-18. doi: 10.7717/peerj.7270.

26. Cook, G.; Burton, L.; Hoogenboom, B. Pre-Participation Screening: The Use of Fundamental Movements As An Assessment of Function-Part 1. North Am. J. Sport. Phys. Ther. 2006, 1, 62-72. doi: 10.1055/s-00341382055.

27. Cook, G.; Burton, L.; Hoogenboom, B. Pre-Participation Screening: The Use of Fundamental Movements As An Assessment of Function-Part 2. North Am. J. Sport. Phys. Ther. 2006, 1, 62, 132-139. doi: 10.1055/s0034-1382055.

28. Cook, G. Movement: Functional movement systems: Screening, asseessmnet and corrective strategies, 1st ed.; Aptos: Lottus Pub: Aptos, California, United States of America, 2011; pp. 31-32.

29. Kiesel, K.B.; Butler, R.J.; Plisky, P.J. Prediction of Injury by Limited and Asymmetrical Fundamental Movement Patterns in American Football Players. J. Sport Rehabil. 2014, 23, 88-94.. doi: 10.1123/JSR.20120130 . 
30. Shojaedin, S.S.; Letafatkar, A.; Hadadnezhad, M.; Dehkhoda, M.R. Relationship between functional movement screening score and history of injury and identifying the predictive value of the FMS for injury. Int. J. Inj. Contr. Saf. Promot. 2014, 21, 355-360.doi: 10.1080/17457300.2013.833942.

31. Bonazza, N.A.; Smuin, D.; Onks, C.A.; Silvis, M.L.; Dhawan, A. Reliability, Validity, and Injury Predictive Value of the Functional Movement Screen. Am. J. Sports Med. 2017, 45, 725-732doi: $10.1177 / 0363546516641937$.

32. Garrison, M.; Westrick, R.; Johnson, M.R.; Benenson, J. Association between the functional movement screen and injury development in college athletes. Int. J. Sports Phys. Ther. 2015, 10, 21-8.

33. Molina-Garcia, P.; Plaza-Florido, A.; Mora-Gonzalez, J.; Torres-Lopez, L.V.; Vanrenterghem, J.; Ortega, F.B. Role of physical fitness and functional movement in the body posture of children with overweight/obesity. Gait Posture 2020, 80, 331-338. doi: 10.1016/j.gaitpost.2020.04.001.

34. García-Pinillos, F.; Roche-Seruendo, L.E.; Delgado-Floody, P.; Mayorga, D.J.; Latorre-Román, P.Á. Original Is there any relationship between functional movement and weight status. Nutr Hosp. 2018, 35, 805-810. doi:10.20960/nh.1670.

35. D'Hondt, E.; Deforche, B.; De Bourdeaudhuij, I.; Lenoir, M. Childhood obesity affects fine motor skill performance under different postural constraints. Neurosci. Lett. 2008, 440, 72-75. doi: 10.1016/j.neulet.2008.05.056.

36. Gushue, D.L.; Houck, J.; Lerner, A.L. Effects of Childhood Obesity on Three-Dimensional Knee Joint Biomechanics During Walking. J Pediatr Orthop. 2005, 25, 763-768. doi: 10.1097/01.PEP.0000155629.67403.

37. Widhalm, H.K.; Seemann, R.; Hamboeck, M.; Mittlboeck, M.; Neuhold, A.; Friedrich, K.; Hajdu, S.; Widhalm, K. Osteoarthritis in morbidly obese children and adolescents, an age-matched controlled study. Knee Surgery, Sport. Traumatol. Arthrosc. 2016, 24, 644-652. doi: 10.1007/s00167-014-3068-4.

38. NCD Risk Factor Collaboration (NCD-RisC). Worldwide trends in body-mass index, underweight, overweight, and obesity from 1975 to 2016: a pooled analysis of 2416 population-based measurement studies in 128.9 million children, adolescents, and adults. Lancet 2017, 390, 2627-264. doi: 10.1016/S01406736(17)32129-3.

39. Quatman-Yates, C.C.; Quatman, C.E.; Meszaros, A.J.; Paterno, M.V.; Hewett, T.E. A systematic review of sensorimotor function during adolescence: a developmental stage of increased motor awkwardness? $\mathrm{Br} \mathrm{J}$ Sports Med. 2012, 46, 649-655. doi:10.1136/bjsm.2010.079616

40. Molina-Garcia, P.; H Migueles, J.; Cadenas-Sanchez, C.; Esteban-Cornejo, I.; Mora-Gonzalez, J.; RodriguezAyllon, M.; Plaza-Florido, A.; Molina-Molina, A.; Garcia-Delgado, G.; D'Hondt, E.; Vanrenterghem, J.; Ortega, F.B. Fatness and fitness in relation to functional movement quality in overweight and obese children. J. Sports Sci., 2019, 37, 878-885. doi: 10.1080/02640414.2018.1532152.

41. Nicolozakes, C.P.; Schneider, D.K.; Rower, B.; Borchers, J.; Hewett, T.E. Influence of Body Composition on Functional Movement Screen ${ }^{\mathrm{TM}}$ Scores in Collegiate Football Players. J. Sport Rehabil. 2017, 27, 431-437. doi:10.1123/jsr.2015-0080.

42. Mitchell, U.H.; Johnson, A.W.; Adamson, B. Relationship between functional movement screen scores, core strength, posture, and body mass index in school children in moldova. J. Strength Cond. Res. 2015, 29, 1172 1179. doi: 10.1519/JSC.0000000000000722.

43. Štefan, L.; Sorić, M.; Devrnja, A.; Podnar, H.; Mišigoj-Duraković, M. Is school type associated with objectively measured physical activity in 15-year-olds? Int. J. Environ. Res. Public Health 2017, 14, 1417. doi: 10.3390/su12166392.

44. Cole, T.J.; Bellizzi, M.C.; Flegal, K.M.; Dietz, W.H. Establishing a standard definition for child overweight and obesity worldwide: International survey. Br. Med. J. 2000, 320, 1240-1243. doi: 10.1136/bmj.320.7244.1240.

45. Smith, C.A.; Chimera, N.J.; Wright, N.J.; Warren, M. Interrater and intrarater reliability of the functional movement screen. J. Strength. Cond. Res. 2013, 27, 982-987. doi: 10.1519/JSC.0b013e3182606df

46. Sterling, M.; Jull, G.; Wright, A. The effect of musculoskeletal pain on motor activity and control. J. Pain 2001, 2, 135-145. doi: 10.1054/jpai.2001.19951.

47. Garrow, J.S.; Webster, J. Quetelet's index (W/H2) as a measure of fatness. Int J Obes. 1985, 9, 147-53.

48. WHO Expert Committee on Physical Status. Physical status: the use and interpretation of anthropometry: report of a WHO Expert Committee; World Health Organization technical report series: Geneva, Switzerland, 1995; pp. 263-306.

49. Wong, S.L.; Leatherdale, S.T.; Manske, S. Reliability and validity of a school-based physical activity questionnaire. Med. Sci. Sports Exerc. 2006, 38, 1593-1600. doi: 10.1249/01.mss.0000227539.58916.35.

50. Rasbash, J.; Steele, F.; Browne, W.J.; Goldstein, H. A user's guide to MLwiN. Centre for Multilevel Modelling, University of Bristol, United Kingdom, 2019. http://www.bristol.ac.uk/cmm/ 
51. Abraham, A.; Sannasi, R.; Nair, R. Normative values for the functional movement screen ${ }^{\mathrm{TM}}$ in adolescent school aged children. Int. J. Sports Phys. Ther. 2015, 10, 29-36.

52. Lester, D.; McGrane, B.; Belton, S.; Duncan, M.J.; Chambers, F. C.; O'Brien, W. The Age-Related Association of Movement in Irish Adolescent Youth. Sports 2017, 5, 1-16. doi: 10.3390/sports5040077.

53. Charlton, C.; Rasbash, J.; Browne, W.J.; Healy, M.; Cameron, B. MLwiN Version 3.04. Centre for Multilevel Modelling, University of Bristol, United Kingdom, 2019.

54. Skelly, A.; Dettori, J.; Brodt, E. Assessing bias: the importance of considering confounding. Evid. Based. Spine. Care. J. 2012, 3, 9-12. doi: 10.1055/s-0031-1298595.

55. Bardenett, S.M.; Micca, J.J.; DeNoyelles, J.T.; Miller, S.D.; Jenk, D.T.; Brooks, G.S. Functional Movement Screen Normative Values and Validity in High School Athletes: Can the Fms ${ }^{\mathrm{TM}}$ Be Used As a Predictor of Injury? Int. J. Sports Phys. Ther. 2015, 10, 303-308.

56. Portas, M.D.; Parkin, G., Roberts, J.; Batterham, A.M. Maturational effect on Functional Movement Screen ${ }^{\mathrm{TM}}$ score in adolescent soccer players. J. Sci. Med. Sport 2016, 19, 854-858. doi: 10.1016/j.jsams.2015.12.001.

57. Anderson, B.E.; Neumann, M.L.; Huxel Bliven, K.C. Functional movement screen differences between male and female secondary school athletes. J. Strength Cond. Res. 2015, 29, 1098-1106. doi: 10.1519/JSC.0000000000000733.

58. Dolphens, M.; Cagnie, B.; Vleeming, A.; Vanderstraeten, G.; Danneels, L. Gender differences in sagittal standing alignment before pubertal peak growth: The importance of subclassification and implications for spinopelvic loading. J. Anat. 2013, 223, 629-640. doi: 10.1111/joa.12119.

59. Gijon-Nogueron, G.; Montes-Alguacil, J.; Martinez-Nova, A.; Alfageme-Garcia, P.; Cervera-Marin, J.A.; Morales-Asencio, J.M. Overweight, obesity and foot posture in children: A cross-sectional study. J. Paediatr. Child Health 2017, 53, 33-37. doi: 10.1111/jpc.13314.

60. Blimkie, C.J.R.; Sale, D.G.; Bar-Or, O. Voluntary strength, evoked twitch contractile properties and motor unit activation of knee extensors in obese and non-obese adolescent males. Eur. J. Appl. Physiol. Occup. Physiol. 1990, 61, 313-318. doi: 10.1007/BF00357619.

61. Duncan, M.J.; Bryant, E.; Stodden, D. Low fundamental movement skill proficiency is associated with high BMI and body fatness in girls but not boys aged 6-11 years old. J. Sports Sci. 2017, 35, 2135-2141. doi: 10.1080/02640414.2016.1258483.

62. D'Hondt, E.; Deforche, B.; De Bourdeaudhuij, I.; Lenoir, M. Relationship between motor skill and body mass index in 5- to 10-year-old children. Adapt. Phys. Act. Q. 2009, 26, 21-37. doi: 10.1123/apaq.26.1.21.

63. Lopes, V.P.; Stodden, D.F.; Bianchi, M.M.; Maia, J.A.R.; Rodrigues, L.P. Correlation between BMI and motor coordination in children. J. Sci. Med. Sport 2012, 15, 38-43. doi: 10.1016/j.jsams.2011.07.005.

64. Li, Y.; Wang, X.; Chen, X.; Dai, B. Exploratory factor analysis of the functional movement screen in elite athletes. J. Sports Sci. 2015, 33, 1166-1172. doi: 10.1080/02640414.2014.986505.

65. Kazman, J.B.; Galecki, J.M.; Lisman, P.; Deuster, P.A.; O'Connor, F.G. Factor structure of the functional movement screen in marine officer candidates. J. Strength Cond. Res. 2014, 28, 672-678. doi: 10.1519/JSC.0b013e3182a6dd83.

66. Wright, M.D.; Chesterton, P. Functional Movement Screen TM total score does not present a gestalt measure of movement quality in youth athletes. J. Sports Sci. 2019, 37, 1393-1402. doi: 10.1080/02640414.2018.1559980.

67. Page, P.; Frank, C.C., Lardner, R. Assessment and treatment of muscle imbalance: The Janda Approach, 1st ed.; Human Kinetics; Champaign, Illionis, United States of America, 2010; pp. 44-46.

68. Teyhen, D.S.; Shaffer, S.W.; Lorenson, C.L.; Halfpap, J.P.; Donofry, D.F.; Walker, M.J.; Dugan, J.L.; Childs, J.D. The Functional Movement Screen: A Reliability Study. J. Orthop. Sport. Phys. Ther. 2012, 42, 530-540. doi: 10.2519/jospt.2012.3838. 